\title{
One-step fermentation for producing xylo-oligosaccharides from wheat bran by recombinant Escherichia coli containing an alkaline xylanase
}

\author{
Jiawen Liư ${ }^{\dagger}$ Cong Liu ${ }^{\dagger}$, Shilei Qiao, Zhen Dong, Di Sun, Jingrong Zhu and Weijie Liu*
}

\begin{abstract}
Background: One-step fermentation is a cheap way to produce xylo-oligosaccharides (XOS), where production of xylanases and XOS is integrated into a single process. In spite of cost advantage, one-step fermentation is still short in yield so far due to the limited exploration. To cope with this issue, production of XOS from wheat bran by recombinant Escherichia coli through one-step fermentation was investigated in this study.

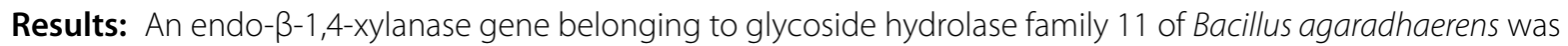
employed to construct recombinant E. coli. This xylanase showed maximal activity at $60^{\circ} \mathrm{C}$ and $\mathrm{pH} 8.0-8.5$. Its activity retained more than $60 \%$ after incubation at $70{ }^{\circ} \mathrm{C}$ for $4 \mathrm{~h}$, showing a good stability. The recombinant E. coli BL21(DE3) could secreted xylanases that directly hydrolyzed de-starched wheat bran to XOS in fermentation medium. The XOS generated from hydrolysis consisted of xylose, xylobiose and xylotriose accounting for $23.1 \%, 37.3 \%$ and 39.6\%, respectively. Wheat bran concentration was found to be the most crucial factor affecting XOS production. The XOS concentration reached $5.3 \mathrm{mg} / \mathrm{mL}$ at $10 \%$ loading of wheat bran, which is higher than those of previous researches. Nitrogen source type could also affect production of XOS by changing extracellular xylanase activity, and glycine was found to be the best one for fermentation. Optimal fermentation conditions were finally studied using response surface optimization. The maximal concentration emerged at $44.3^{\circ} \mathrm{C}, \mathrm{pH} 7.98$, which is affected by characteristics of the xylanase as well as growth conditions of E. coli.
\end{abstract}

Conclusions: This work indicates that the integrated fermentation using recombinant $E$. coli is highly competitive in cost and final concentration for producing XOS. Results can also provide theoretical basis for large-scale production and contribute to the wide adoption of XOS.

Keywords: Prebiotics, Bacillus agaradhaerens, Single-step fermentation, Xylanase, Response surface optimization

*Correspondence: leonliu2013@126.com

†iawen Liu and Cong Liu contributed equally to this work

Jiangsu Key Laboratory of Phylogenomics and Comparative Genomics,

School of Life Science, Jiangsu Normal University, No. 101, Shanghai Road,

Tongshan District, Xuzhou 221116, Jiangsu Province, China

\begin{abstract}
Background
Prebiotics, namely some kinds of oligosaccharides, can specifically promote the activity of beneficial bacteria in gastrointestinal tract $[1,2]$. With insight into the effect of gut microbiota on human overall health, prebiotics have been the hotspot in consumption and research currently [3]. Xylo-oligosaccharides (XOS) are emerging probiotics which consist of several $\beta-1,4$ linked xylose units [4]. They have been attached importance to recent years due
\end{abstract}


to remarkable prospect of application in food, medicine, poultry and other fields [5-7]. Furthermore, XOS are more efficient than other prebiotics in enhancing growth of certain bifidobacteria and in protecting lactobacilli under stress environments [8-10]. XOS also present good heat and $\mathrm{pH}$ stability, which is beneficial to retaining more nutritional properties in digestive tract [11]. Because of these advantages, market demand for XOS is rising quickly and expected to reach 130 million U.S. dollars in 2023 at an annual growth of 5.3\% [12].

Enzymatic hydrolysis is one of the major methods to produce XOS, which is more environmentally friendly and generates less undesired by-products than chemical hydrolysis [13]. Xylanases are the critical factor for enzymatic production of XOS, which act on backbone of xylan and convert it into XOS as well as xylose. Xylanases belonging to glycoside hydrolase (GH) family 11 attack unsubstituted sites of xylan, whose hydrolysate mainly consists of xylobiose and xylotriose; GH10 xylanases can accommodate a decorated xylopyranosyl residue at -1 subsite, resulting in production of both linear and substituted XOS with low degree of polymerization (DP); GH30 xylanases prefer branched xylan than the linear one so substituted XOS are their principal products $[14,15]$. Hydrolyzing extracted xylan or raw lignocellulosic biomass using these xylanases to produce XOS has been widely reported, and XOS yields are very attractive in some works $[16,17]$. However, preparation of these purified enzymes is unwieldy and costly. In addition, high temperature is commonly needed for an efficient enzymatic hydrolysis, which also prejudices the cost of production process $[18,19]$. To cope with these issues, some researches devoted to integrating production of xylanases and XOS into a single process. In such process, microorganisms extracellularly secrete xylanases and meanwhile, these enzymes directly convert xylan or lignocellulosic biomass into XOS in medium. For example, a wild-type Bacillus subtilis was reported to produce XOS by direct fermentation utilizing brewers' spent grain, and XOS could yield further increase when $B$. subtilis was genetically modified [20]. Some fungi, such as Trichoderma reesei and Aspergillus nidulans, exhibited potential of producing XOS in one-step fermentation as well [21, 22]. These integrated production of XOS left out separate process for preparing xylanases, and generally adopted mild fermentation conditions, which contributes to overcoming cost challenge [12]. Nevertheless, XOS yields of one-step fermentation are commonly disadvantaged comparing with those of enzymatic hydrolysis. Indeed, yields can be improved by optimizing types of medium, substrates, fermentation microorganisms and conditions, but researches about these issues are scarce. For example, only a few bacillus and fungi are employed for one-step fermentation so far. These microorganisms, however, can all utilize XOS as carbon source, which prejudices the accumulation of XOS in medium. In addition, critical restriction limiting XOS production remains unknown for such integrated fermentation, which leads to difficulty in substantial improvement in yield.

Escherichia coli has been used to produce food additives and drugs for decades, which has been proved to be safe and reliable [23, 24]. E. coli is probably suited to fermentation for producing XOS because it cannot consume this kind of oligosaccharides [25]. However, feasibility of one-step fermentation employing $E$. coli lacks sufficient study. Wheat bran is a xylan-rich by-product of white flour milling and has been used as cheap raw materials for XOS production previously $[26,27]$. Bacillus agaradhaerens C9 is an alkaliphilic strain with lignocellulosedegrading ability. Secretion of alkali-tolerant xylanases by $B$. agaradhaerens $C 9$ was verified in our previous work [28]. Bioinformatics analysis of its genome revealed an GH11 xylanase that was named Baxyl11. In this study, Baxyl11 was expressed using E. coli BL21(DE3) and enzymatic characteristics of recombinant Baxyl11 (rBaxyl11) were then investigated. Moreover, producing XOS from wheat bran by the recombinant E. coli BL21(DE3) containing rBaxyl11 was carried out. Effects of wheat bran concentration, nitrogen source type and fermentation conditions ( $\mathrm{pH}$ and temperature) on XOS production were finally investigated. These results would contribute to overcoming yield and cost challenge in the production of XOS, and promote its wide adoption.

\section{Results}

\section{Enzymatic characteristics of rBaxyl11}

Baxyl11 gene was cloned from genomic DNA of $B$. agaradhaerens $\mathrm{C} 9$ and ligated with plasmid $\mathrm{pET} 22 \mathrm{~b}(+)$. rBaxyl11 was then expressed using E. coli BL21(DE3). The purified rBaxyl11 showed electrophoretic homogeneity and its molecular weight corresponded to the calculated value of $28.9 \mathrm{kD}$ (Fig. 1a). rBaxyl11 presented hydrolytic activity to glucuronoxylan and arabinoxylan but not to cellulose, mannan, starch and 4-nitrophenyl-beta-D-xylopyranoside (pNPX), which demonstrated that $r B a x y l 11$ is an endoxylanase.

To evaluate its catalytic activities, kinetic parameters of rBaxyl11 against arabinoxylan and glucuronoxylan were measured (Table 1). $\mathrm{V}_{\max }$ and $\mathrm{K}_{\text {cat }}$ against arabinoxylan were approximately two times as high as those against glucuronoxylan, showing higher activity against arabinoxylan. However, lower $K_{m}$ against glucuronoxylan indicated the preference for such polysaccharide than arabinoxylan. As a result, the $\mathrm{K}_{\mathrm{cat}} / \mathrm{K}_{\mathrm{m}}$ of $\mathrm{rBaxyl11}$ against glucuronoxylan was higher than that against arabinoxylan. 


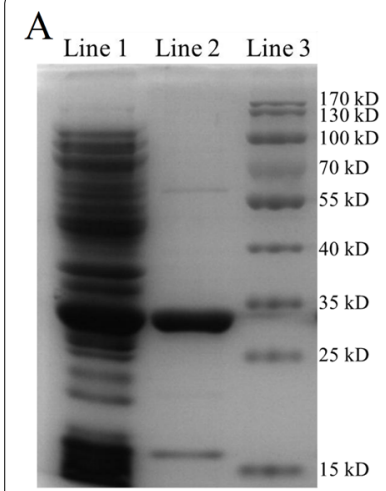

B

Baxyl11 MRQKKLTLILAFLVCFALTLPAEIIQAQIVTDNSIGNHDGYDYEFWKDSGG

Baxyl11 SGTMILNHGGTFSAQWNNVNNILFRKGKKFNETQTHQQVGNMS INYGANFO BadX SGTMILNHGGTFSAQWNNVNNILFRKGKKFNETQTHQQVGNMS INYGANFQ

Baxyl11 PNGNAYLCVYGWTVDPLVEYYIVDSWGNWRPPGATPKGTITVDGGTYDIYE

$\operatorname{BadX}$

PNGNAYLCVYGWTVDPLVEYYIVDSWGNWRPPGATPKGTITVDGGTYDIYE

Baxyl11 TLRVNQPSIKGIATFKQYWSVRRSKRTSGTISVSNHFRAWENLGMNMGKMY

BadX TLRVNQPSIKGIATFKQYWSVRRSKRTSGTISVSNHFRAWENLGMNMGKMY

Fig. 1 Electrophoresis and sequence analysis of rBaxyl11. a Sodium dodecyl sulfate polyacrylamide gel electrophoresis analysis of rBaxyl11. Line 1: soluble cell extract containing rBaxyl1 1; Line 2: rBaxyl11 after purification; Line 3: marker. b Sequence alignment of Baxyl11 and BadX. Amino acid residues belonging to signal peptide are marked with yellow background. Different amino acid residues between Baxyl11 and BadX are marked with green background

Table 1 Kinetic parameters of rBaxyl11 for xylans

\begin{tabular}{lclcl}
\hline Substrate & $\mathbf{V}_{\max }(\boldsymbol{\mu M} / \mathbf{s})$ & $\mathrm{K}_{\mathrm{cat}}(\mathbf{s})$ & $\mathrm{K}_{\mathbf{m}}(\mathbf{g} / \mathbf{L})$ & $\mathrm{K}_{\text {cat }} / \mathbf{K}_{\mathbf{m}}(\mathbf{L} / \mathbf{g} / \mathbf{s})$ \\
\hline Arabinoxylan & $44.2 \pm 3.7$ & $599.0 \pm 49.7$ & $10.9 \pm 0.9$ & $55.0 \pm 0.3$ \\
Glucuronoxylan & $24.3 \pm 0.6$ & $330.1 \pm 7.7$ & $4.1 \pm 0.1$ & $79.7 \pm 1.2$
\end{tabular}

Concentration of rBaxyl11 was $220 \mathrm{nM}$ for measurement. All data are presented as mean \pm standard deviation $(\mathrm{n}=3)$
To investigate the optimal conditions for catalysis, activities of rBaxyl11 were measured at different temperatures and $\mathrm{pH}$ values (Fig. 2a, b). rBaxyl11 showed highest activity at $60{ }^{\circ} \mathrm{C}$ and its optimal $\mathrm{pH}$ ranged from 8.0 to 8.5 , indicating it is an alkaline xylanase. Stability of rBaxyl11 was then studied (Fig. 2c, d). Activity of
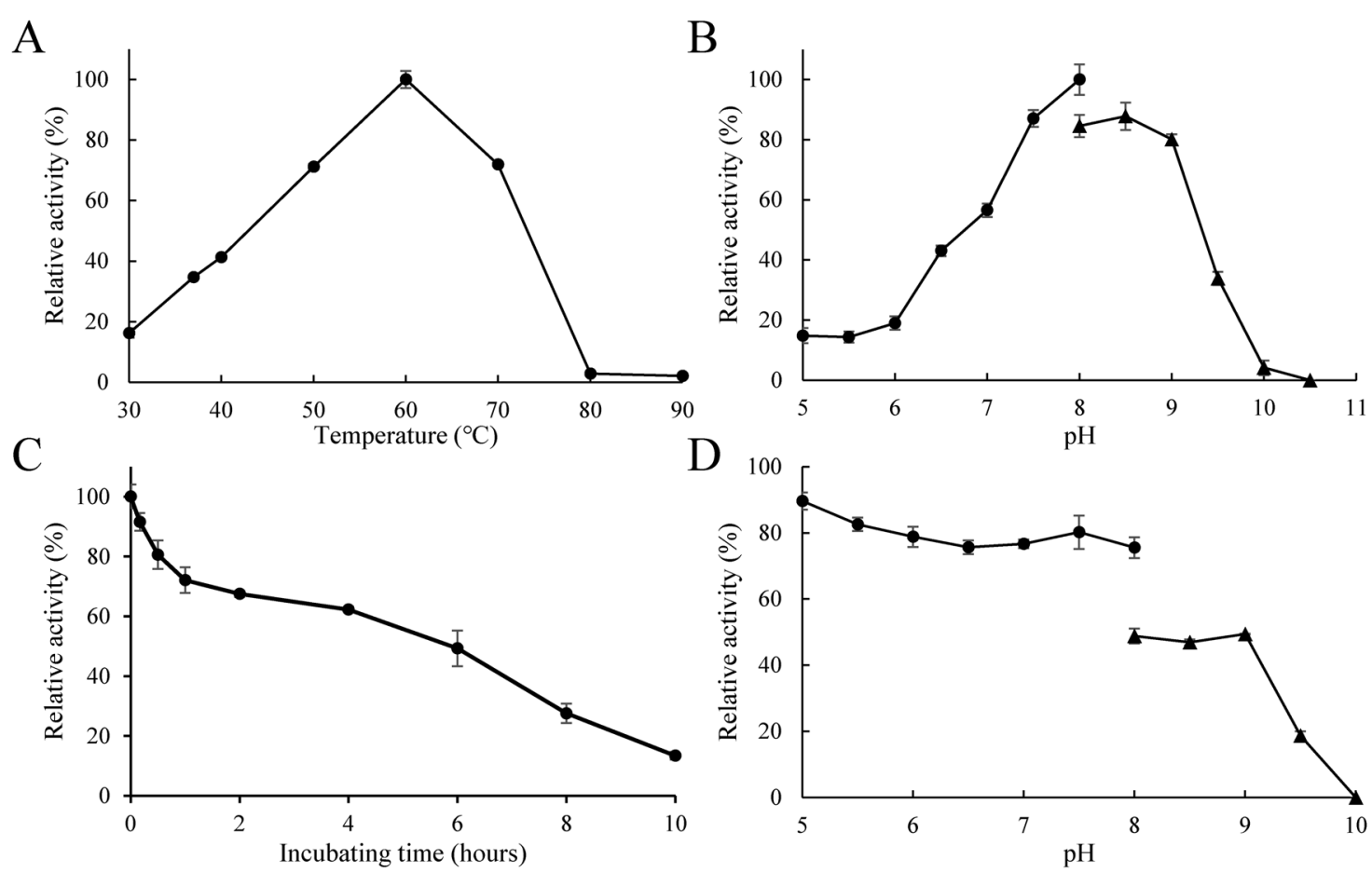

Fig. 2 Effect of temperature and pH on activity and stability of rBaxyl11. a Effect of temperature on activity of rBaxyl11. $\mathbf{b}$ Effect of pH on activity of rBaxyl11. c Effect of temperature on stability of rBaxyl11. d Effect of pH on stability of rBaxyl11. In (a) and (b), the maximal activity was designated as $100 \%$. In (c) and (d), activity of enzyme without incubation was designated as 100\%. Measurement at pH 5.0-8.0 and 8.0-10.5 was carried out in $\mathrm{Na}_{2} \mathrm{HPO}_{4}-\mathrm{NaH}_{2} \mathrm{PO}_{4}$ buffer and $\mathrm{Na}_{2} \mathrm{CO}_{3}-\mathrm{NaHCO}_{3}$ buffer, respectively. All data are presented as means \pm standard deviations $(n=3)$ 
rBaxyl11 retained more than $80 \%$ after incubation at $70{ }^{\circ} \mathrm{C}$ for $30 \mathrm{~min}$, and even after $4 \mathrm{~h}, 60 \%$ of its activity could be maintained. Moreover, rBaxyl11 showed good stability when incubated at the $\mathrm{pH}$ ranging from 5.0 to 9.0, which is commonly the appropriate $\mathrm{pH}$ range for fermentation.

\section{One-step fermentation for XOS production}

To save cost and simplify process, direct fermentation by rBaxyl11-transformed E. coli BL21(DE3) to produce XOS from wheat bran was carried out. Starch in wheat bran was removed in advance for a better XOS yield. Employ of the recombinant $E$. coli BL21(DE3) in the presence of isopropyl-1-thio- $\beta$-D-galactopyranoside (IPTG) and wheat bran for fermentation resulted in a reducing sugar yield of $1.41 \mathrm{mg} / \mathrm{mL}$ at the 24th hour (Fig. 3a). By contrast, fermentation without wheat bran or using $E$. coli BL21(DE3) containing raw plasmid only produced negligible reducing sugars, demonstrating that $\mathrm{r} B a x y l 11$ from E. coli could produce XOS by acting on wheat bran in such one-step fermentation.

In the presence of $\mathrm{r} B a x y l 11$ and wheat bran, xylanase activity increased rapidly in the first $6 \mathrm{~h}$ and slowly then (Fig. 3b). Activity in the medium without IPTG showed similar trend but at lower level. It is noteworthy that use of IPTG raised xylanase activity by $40 \%$ while only increased XOS concentration by $18 \%$, suggesting that xylanase activity is not the most important factor to yield (see "Effect of nitrogen source type on one-step fermentation" section for details).

\section{Product composition of rBaxyl11 acting on wheat bran}

To study the product composition of $\mathrm{r} B a x y l 11$ acting on wheat bran, its hydrolysate was analyzed using high pressure ion chromatography (HPIC). Results demonstrated that xylose, xylobiose and xylotriose are the primary product (Fig. 4a). Further quantitative analysis basing on chromatogram showed that xylose, xylobiose and xylotriose respectively accounted for $23.1 \%, 37.3 \%$ and $39.6 \%$ (Fig. 4b). In other words, about $77 \%$ of its product is lowDP XOS when $\mathrm{r} B a x y l 11$ hydrolyzed wheat bran.

\section{Effect of wheat bran concentration on one-step fermentation}

Effect of wheat bran concentration on XOS yield was investigated here. As showed in Fig. 5a, XOS concentration increased with wheat bran concentration in $0-10 \%$ of loading range, and further raise in substrate loading would lead to an excessive viscosity of medium. At $10 \%$ of wheat bran concentration, $6.9 \mathrm{mg} / \mathrm{mL}$ of reducing sugar was obtained. That means the XOS concentration reached $5.3 \mathrm{mg} / \mathrm{mL}$ (excluding xylose), which is very considerable.

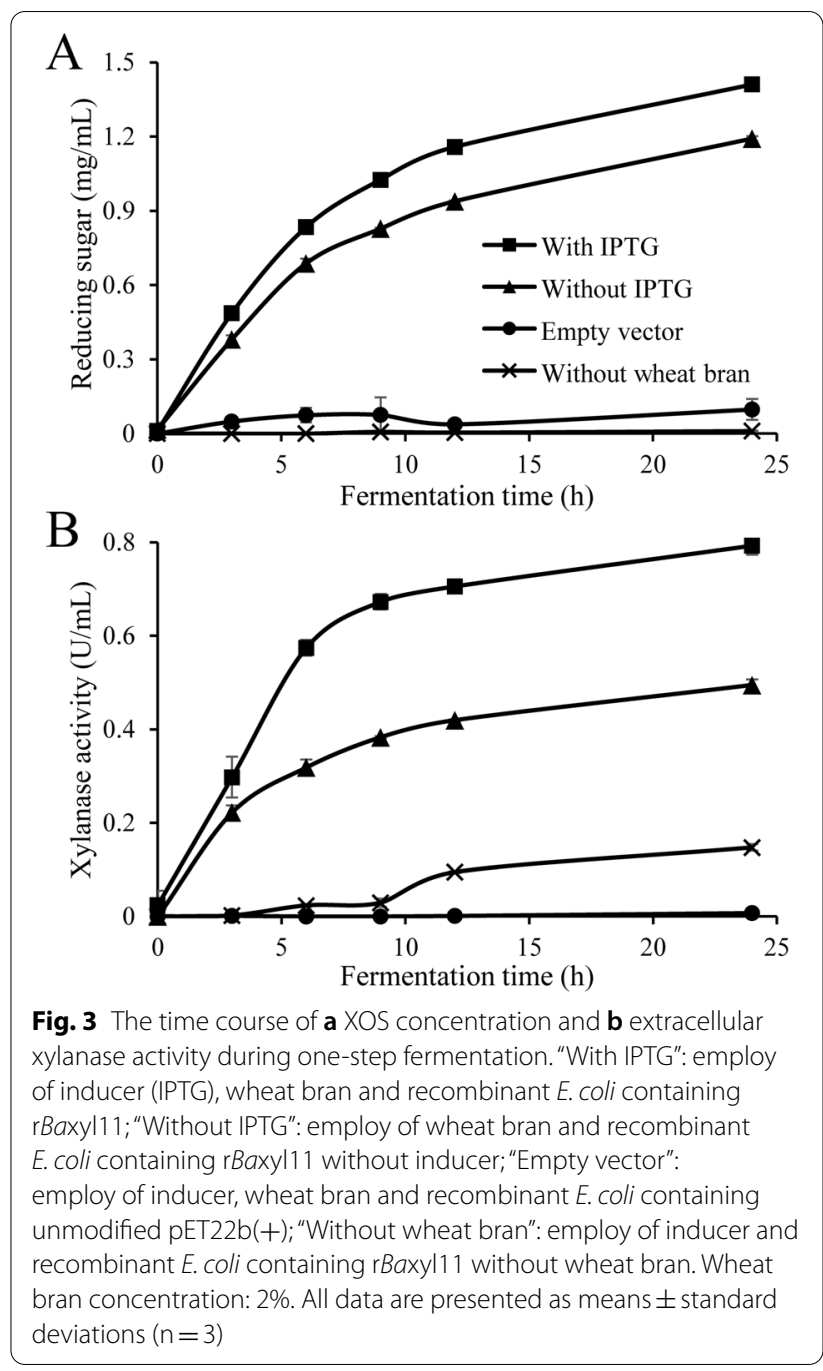

To study how wheat bran concentration affects production of XOS, xylanase activity and growth of $E$. coli BL21(DE3) were also measured. Xylanase activity increased with wheat bran concentration while the biomass of $E$. coli BL21(DE3) showed opposite trend, indicating that high-concentration wheat bran stimulated the synthesis and secretion of $\mathrm{r} B a x y l 11$ and inhibited the growth of E. coli BL21(DE3) (Fig. 5). A high xylanase activity would contribute to XOS production, but the huge increase of final concentration was not exclusively due to this reason. Specifically, XOS concentration increased nearly 16 -fold when wheat bran concentration raised tenfold from 1 to $10 \%$, and meanwhile, xylanase activity only increased by $103 \%$. It is obvious that augmentation of XOS yield resulted from combined effect of the increase in both wheat bran concentration and xylanase activity, where the former contributed more. In other words, substrate concentration 

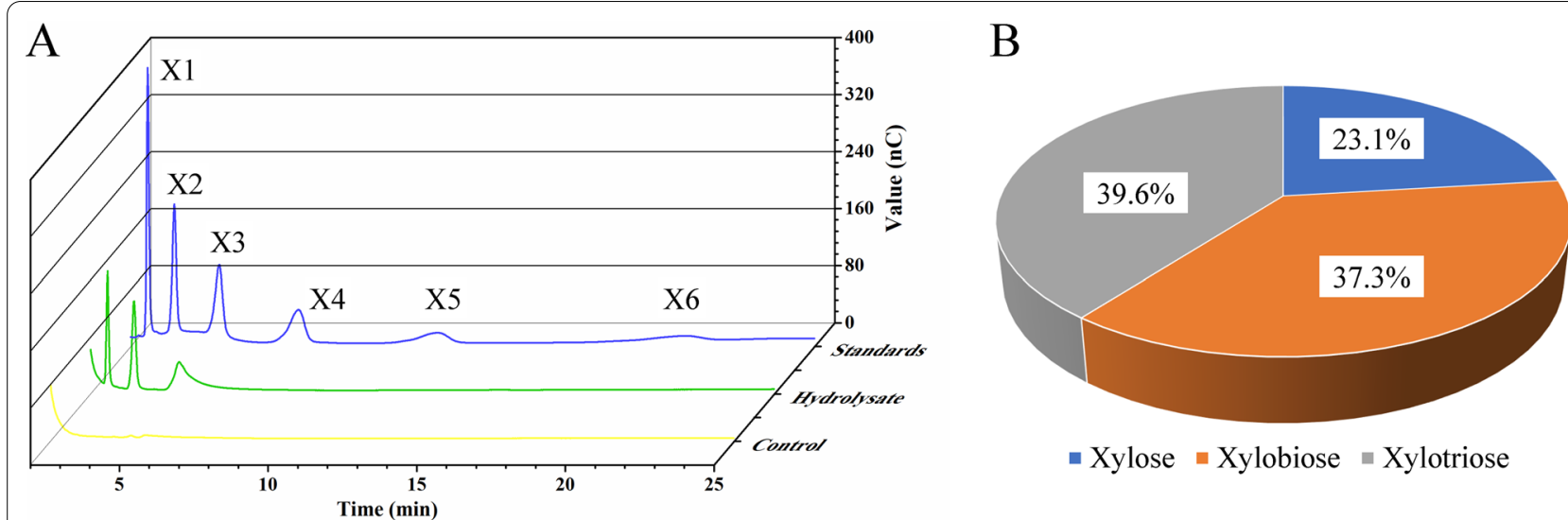

$\square$ Xylose $\backsim$ Xylobiose $\backsim$ Xylotriose

Fig. 4 Product composition of rBaxyl11 acting on wheat bran analyzed by HPIC. a Product composition of the hydrolysis. "Standards": mixture of xylose, xylobiose, xylotriose, xylotetraose, xylopentaose and xylohexaose with respective concentration of $2 \mathrm{mg} / \mathrm{mL}$; "Hydrolysate": XOS produced by rBaxyl11 from wheat bran; "Control": sample of hydrolysate without employ of rBaxyl11. b Quantitative analysis of xylose and XOS produced by rBaxyl11
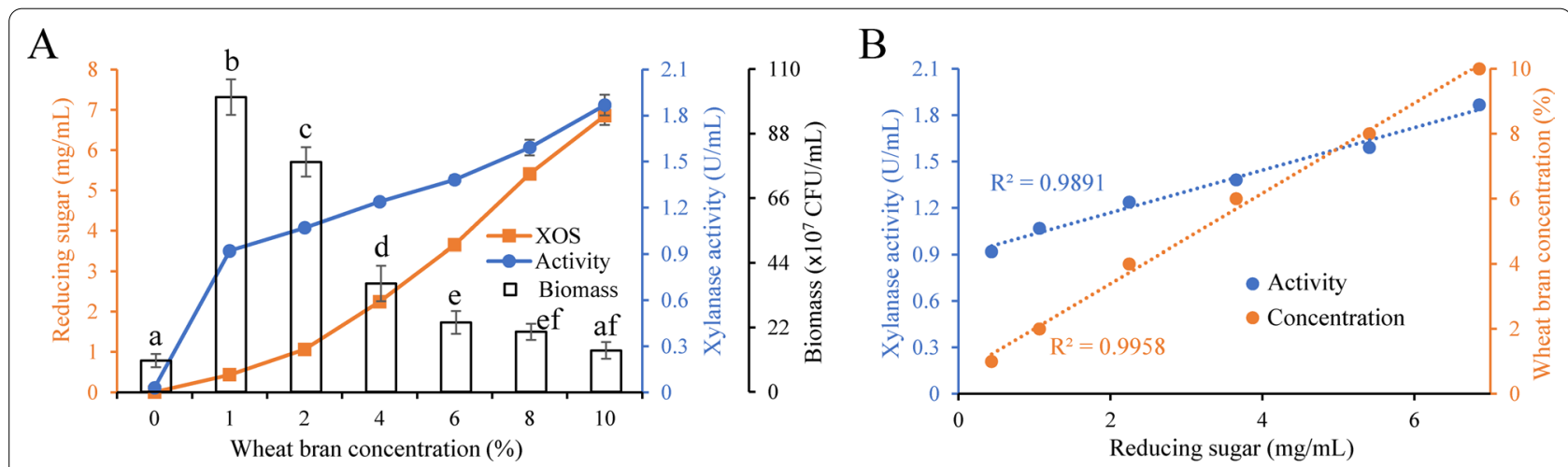

Fig. 5 Effect of wheat bran concentration on one-step fermentation. a Effect of wheat bran concentration on XOS production, xylanase activity and biomass of recombinant E. coli. b Correlation between XOS concentration and xylanase activity as well as wheat bran concentration. Fermentation time: 12 h. Temperature: $37^{\circ} \mathrm{C}$. Initial pH: 7.0. In (a), data are presented as means \pm standard deviations $(n=3)$

is the decisive factor to XOS production in such fermentation process instead of enzymatic activity.

\section{Effect of nitrogen source type on one-step fermentation}

Effect of nitrogen source type on one-step fermentation was investigated here (Fig. 6a). Measurement of reducing sugar indicated that maximal XOS concentration was obtained when using glycine as nitrogen source, which is slightly higher than that using yeast extract ( $\mathrm{p}$ value $=0.065$ ). The lowest three yields showed when $\mathrm{NH}_{4} \mathrm{NO}_{3}, \mathrm{NaNO}_{3}$ and $\mathrm{NH}_{4} \mathrm{SO}_{4}$ were employed, indicating such inorganic salts are not suited to production of XOS.

The correlation analysis was then conducted to evaluate the effect of nitrogen sources on XOS. To avoid the effect of difference in nitrogen sources on enzymatic activity assay, medium after dialysis was also employed for measurement (Fig. 6b). Results demonstrated a positive linear correlation between XOS concentration and xylanase activity regardless of whether medium was treated with dialysis. By comparison, no credible correlation between XOS concentration and biomass was observed. Therefore, types of nitrogen source affected XOS production mainly by changing xylanase activity.

\section{Optimizing XOS production by response surface methodology}

To study effect of fermentation conditions, temperature, $\mathrm{pH}$ and glycine concentration were chosen as variables for optimization using Box-Behnken design. After 12-h fermentation, concentrations of reducing sugars varied in the range of $1.629-1.895 \mathrm{mg} / \mathrm{mL}$ (Table 2 and 

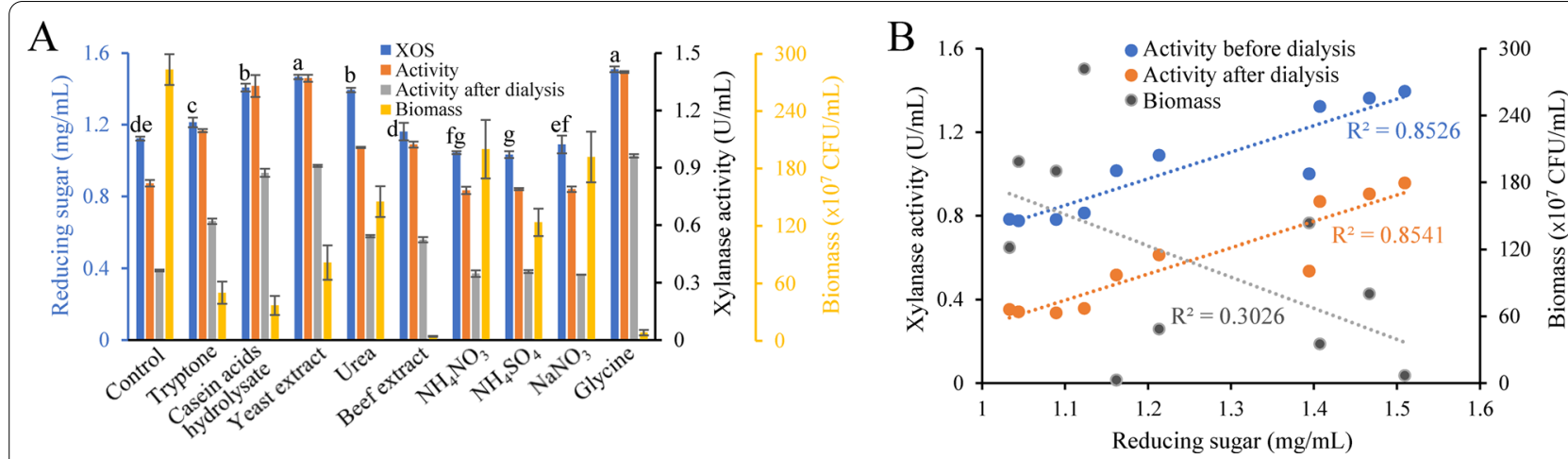

Fig. 6 Effect of nitrogen source type on one-step fermentation. a Effect of nitrogen source type on XOS production, xylanase activity and biomass of recombinant E. coli. "Activity": xylanase activity measured using supernatant of medium; "Activity after dialysis": xylanase activity measured using dialysis-treated supernatant of medium. b Correlation between XOS concentration and xylanase activity as well as wheat bran concentration. Wheat bran concentration: $2 \%$. Fermentation time: $12 \mathrm{~h}$. Temperature: $37^{\circ} \mathrm{C}$. Initial pH: 7.0. In (a), data are presented as means \pm standard deviations $(\mathrm{n}=3$ )

Table 2 Experimental design to study the effect of $\mathrm{pH}$, fermentation temperature and glycine concentration on XOS production

\begin{tabular}{lllll}
\hline Run & pH & $\begin{array}{l}\text { Temperature } \\
\left({ }^{\circ} \mathbf{C}\right)\end{array}$ & Glycine (\%) & Concentration $(\mathrm{mg} / \mathbf{m L})$ \\
\hline 1 & 8.1 & 40 & 0.2 & $1.629 \pm 0.008$ \\
2 & 8.1 & 44 & 2.6 & $1.895 \pm 0.009$ \\
3 & 7.6 & 48 & 2.6 & $1.780 \pm 0.009$ \\
4 & 7.6 & 44 & 0.2 & $1.673 \pm 0.014$ \\
5 & 8.1 & 48 & 5.0 & $1.721 \pm 0.014$ \\
6 & 8.6 & 44 & 5.0 & $1.784 \pm 0.039$ \\
7 & 8.1 & 40 & 5.0 & $1.721 \pm 0.013$ \\
8 & 8.1 & 44 & 2.6 & $1.895 \pm 0.009$ \\
9 & 8.1 & 48 & 0.2 & $1.709 \pm 0.018$ \\
10 & 8.1 & 44 & 2.6 & $1.895 \pm 0.009$ \\
11 & 7.6 & 44 & 5.0 & $1.862 \pm 0.044$ \\
12 & 8.6 & 44 & 0.2 & $1.743 \pm 0.003$ \\
13 & 7.6 & 40 & 2.6 & $1.703 \pm 0.011$ \\
14 & 8.1 & 44 & 2.6 & $1.895 \pm 0.009$ \\
15 & 8.6 & 48 & 2.6 & $1.714 \pm 0.008$ \\
16 & 8.1 & 44 & 2.6 & $1.895 \pm 0.009$ \\
17 & 8.6 & 40 & 2.6 & $1.685 \pm 0.055$ \\
\hline
\end{tabular}

All data are presented as mean \pm standard deviation $(n=3)$

Fig. 7). Glycine concentration is the most influential variable with $\mathrm{p}$-value $=0.0006$, followed by temperature with $\mathrm{p}$ value $=0.0132$. It was predicted that the optimal concentration of $1.904 \mathrm{mg} / \mathrm{mL}$ would be obtained at $44.3{ }^{\circ} \mathrm{C}$, pH 7.98 with $3.36 \%$ of glycine, which corresponds approximately to the central-point condition of the design. The optimal $\mathrm{pH}$ for fermentation corresponded to that of catalysis by $\mathrm{r}$ Baxyl11 (Fig. 2b), while the optimal temperature is lower than that for catalysis $\left(60^{\circ} \mathrm{C}\right)$ and higher than the best growth temperature of E. coli $\left(37^{\circ} \mathrm{C}\right)$.

\section{Discussion}

High cost is a challenge limiting the enzymatic production of XOS. One-step fermentation is a cost-efficient way to produce XOS, but its yield was commonly modest comparing with that of enzymatic hydrolysis (Table 3). For example, hydrolyzing mahogany employing a xylanase of Clostridium resulted in a XOS concentration of $4.5 \mathrm{mg} / \mathrm{mL}$ [29]. The concentrations could even exceed $8 \mathrm{mg} / \mathrm{mL}$ when using extracted xylan as substrate [16]. By comparison, only $0.8-1.1 \mathrm{mg} / \mathrm{mL}$ of XOS were obtained employing B. subtilis or Trichoderma species in one-step fermentation despite optimization [20, 21]. A higher concentration of $3.2 \mathrm{mg} / \mathrm{mL}$ was obtained when using wheat middlings and B. subtilis, but the fermentation time, $48 \mathrm{~h}$, was less competitive [30]. This study described a considerable XOS concentration of $5.3 \mathrm{mg} / \mathrm{mL}$ with only 12 -h fermentation, which is much higher than those of previous works. Moreover, substrate concentration was found to be the most influential factor to XOS production here. This is probably the cause of modest XOS yields in previous reports because XOS yield were prejudiced by a large loading of substrates using B. subtilis and fungi [20,21]. Therefore, employing E. coli BL21(DE3) is promising to eliminate the disadvantage in XOS production by onestep fermentation.

Considerable reducing sugar $(1.19 \mathrm{mg} / \mathrm{mL}$ at the 24 th hour) were produced even without IPTG, which could be attributed to induction of certain saccharides from wheat bran. Further study indicated that XOS concentration induced by wheat bran alone reached $78 \%$ of the maximum with $1 \mathrm{mM}$ of IPTG, and adding only a small amount of IPTG $(0.02 \mathrm{mM})$ could lead to the maximal 

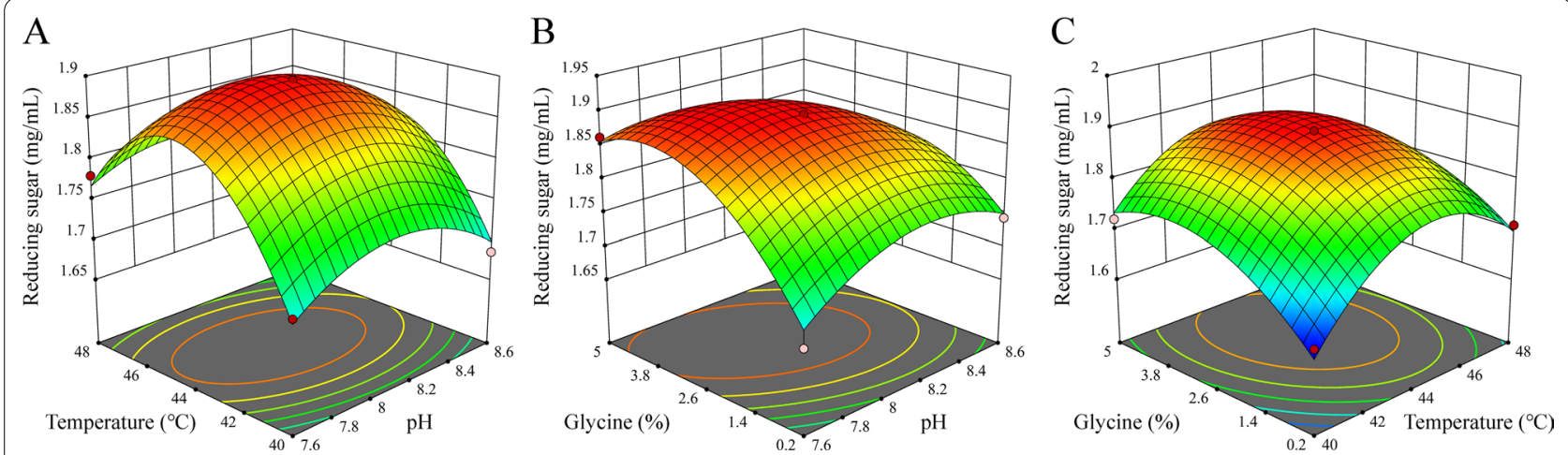

Fig. 7 Response surface showing effect of temperature, $\mathrm{pH}$ and glycine concentration on XOS production. $\mathbf{a}$ Effect of temperature and $\mathrm{pH}$ on XOS production. $\mathbf{b}$ Effect of glycine concentration and $\mathrm{pH}$ on XOS production. $\mathbf{c}$ Effect of glycine concentration and temperature on XOS production. Wheat bran concentration: $2 \%$. Fermentation time: $12 \mathrm{~h}$. All experiments were conducted in triplicate

Table 3 XOS production by enzymatic hydrolysis and one-step fermentation

\begin{tabular}{|c|c|c|c|c|c|c|}
\hline \multirow[t]{2}{*}{ Substrate } & \multirow[t]{2}{*}{ Enzyme or strain } & \multirow{2}{*}{$\begin{array}{l}\text { Reaction } \\
\text { time }(h)^{\mathrm{a}}\end{array}$} & \multicolumn{2}{|c|}{ XOS yields ${ }^{b}$} & \multirow[t]{2}{*}{ XOS production method } & \multirow[t]{2}{*}{ References } \\
\hline & & & $\mathrm{mg} / \mathrm{mL}^{\mathrm{c}}$ & $\mathrm{mg} / \mathrm{g}$ substrate $\mathrm{d}^{\mathrm{d}}$ & & \\
\hline Wheat bran & Engineering E. coli BL21(DE3) & 12 & $0.8-5.3^{e}$ & $53-80^{e}$ & One-step fermentation $\left(37^{\circ} \mathrm{C}\right)$ & This study \\
\hline Wheat middlings & Bacillus subtilis & 48 & $3.2^{\mathrm{e}}$ & $64^{e}$ & One-step fermentation $\left(37^{\circ} \mathrm{C}\right)$ & {$[30]$} \\
\hline Brewers'spent grain & Engineering Bacillus subtilis & 12 & 1.1 & 34 & One-step fermentation $\left(45^{\circ} \mathrm{C}\right)$ & [20] \\
\hline Brewers'spent grain & Trichoderma reesei & 72 & 0.8 & 40 & One-step fermentation $\left(30^{\circ} \mathrm{C}\right)$ & [21] \\
\hline Rice husk & Engineering Aspergillus nidulans & 48 & - & 24 & One-step fermentation $\left(37^{\circ} \mathrm{C}\right)$ & {$[22]$} \\
\hline Pistachio shell & Commercial xylanase & 10 & $2.7^{\mathrm{e}}$ & - & Enzymatic hydrolysis $\left(45^{\circ} \mathrm{C}\right)$ & [43] \\
\hline Mahogany & $\begin{array}{l}\text { Xylanase from Clostridium strain } \\
\mathrm{BOH} 3\end{array}$ & 24 & $4.5^{e}$ & $90^{e}$ & Enzymatic hydrolysis $\left(50^{\circ} \mathrm{C}\right)$ & [29] \\
\hline Sugarcane bagasse & Xylanase from Bacillus subtilis & 15 & 3.6 & 119 & Enzymatic hydrolysis $\left(50^{\circ} \mathrm{C}\right)$ & [44] \\
\hline Rice straw & Commercial xylanase & 24 & $0.1^{\mathrm{e}}$ & $2^{\mathrm{e}}$ & Enzymatic hydrolysis $\left(50^{\circ} \mathrm{C}\right)$ & [45] \\
\hline Rice straw & Xylosidase from Weissella cibaria & 10 & $2.6^{e}$ & $70^{e}$ & Enzymatic hydrolysis $\left(37^{\circ} \mathrm{C}\right)$ & [46] \\
\hline Beechwood xylan & $\begin{array}{l}\text { Xylanase from Mycothermus thermo- } \\
\text { philus }\end{array}$ & 12 & $8.0-8.8^{e}$ & $800-880^{e}$ & Enzymatic hydrolysis $\left(65^{\circ} \mathrm{C}\right)$ & [16] \\
\hline Xylan from corn cobs & $\begin{array}{l}\text { Xylanase from Thermomyces lanugi- } \\
\text { nosus }\end{array}$ & 8 & 6.9 & 345 & Enzymatic hydrolysis $\left(45^{\circ} \mathrm{C}\right)$ & [47] \\
\hline Xylan from data seed & Xylanase from Aspergillus niger & 4 & $4.1^{\mathrm{e}}$ & $411^{\mathrm{e}}$ & Enzymatic hydrolysis $\left(38^{\circ} \mathrm{C}\right)$ & [48] \\
\hline Xylan from vetiver grass & $\begin{array}{l}\text { Xylanase from Aureobasidium melano- } \\
\text { genum }\end{array}$ & 92 & 4.7 & 194 & Enzymatic hydrolysis $\left(28^{\circ} \mathrm{C}\right)$ & [49] \\
\hline
\end{tabular}

\footnotetext{
${ }^{a}$ Reaction time indicates the hydrolysis or fermentation time when XOS concentration reaches the presented value

${ }^{\mathrm{b}}$ Xylose is not included

' Yields are presented as final concentration $(\mathrm{mg} / \mathrm{mL})$ of XOS in fermentation medium

${ }^{\mathrm{d}}$ Yields are presented as mass $(\mathrm{mg})$ of XOS obtained from a gram of substrate

e These data are measured using liquid chromatogram and others are measured using DNS method
}

XOS concentration as well as xylanase activity in the fermentation medium (Additional file 1: Fig. S1). Also, E. coli BL21(DE3) could still grow and secrete xylanases without additional nitrogen source, suggesting certain components like crude protein of wheat bran could be utilized as nitrogen source (Fig. 6). These results suggested that wheat bran not only acted as substrate for
XOS production, but also played an important role in stimulating the secretion of $\mathrm{r} B a x y l 11$ and served as nutrient, which is conducive to economical use of extra inducer and to saving cost. Fermentation without wheat bran or using E. coli BL21(DE3) containing raw plasmid also produced tiny amounts of reducing sugar, which probably resulted from reducing metabolites secreted by E. coli BL21(DE3) (Fig. 3). 
Xylanase activity is another factor influencing XOS production. For example, type of nitrogen source actually affected XOS production mainly by changing xylanase activity (Fig. 4), and the increase of activity also contributed to the production in the experiment of optimizing wheat bran concentration (Fig. 5). However, a huge raise in xylanase activity commonly leading to a limited increase in XOS concentration (Fig. 3 and Fig. 6a), suggesting that mere pursuit of high activity or large loading of xylanase could be less effective than expected in largescale production of XOS. Interestingly, the biomass of $E$. coli BL21(DE3) was very low when the optimal nitrogen source or high wheat bran concentration was employed (Figs. 5a, 6a). It seems that ideal condition for fermentation prejudices bacteria growth but stimulates the accumulation of heterologous proteins.

The GH11 xylanase of B. agaradhaerens AC13, BadX, was previously reported to hydrolyze pNPX [31]. However, $\mathrm{r}$ Baxyl11 of $B$. agaradhaerens $C 9$ was actually an endo- $\beta-1,4$-xylanase, and was not able to act on pNPX according to our results. This difference could be attributed to the change from lysine to glutamic acid of amino acid sequence (Fig. 1b). Xylobiose and xylotriose were the main products by $r$ Baxyl11 acting on wheat bran. Such low-DP XOS commonly present better prebiotic efficacy [32, 33]. Moreover, alkaline environment is optimal for fermentation by E. coli containing $\mathrm{r} B a x y l 11$, which could prevent hemicellulose from autohydrolysis during heat sterilization thereby avoiding undesired saccharides [34]. Therefore, $\mathrm{rBaxyl} 11$ is promising to one-step fermentation for XOS production with advantages in, for example, specificity and stability. The best fermentation temperature is $44.3^{\circ} \mathrm{C}$, which is affect by both of the optimal temperature for catalysis by $\mathrm{r} B a x y l 11\left(60{ }^{\circ} \mathrm{C}\right)$ and for growth of E. coli $\left(37^{\circ} \mathrm{C}\right)$. Comparing with enzymatic hydrolysis using purified xylanases at high temperature, one-step fermentation employing recombinant $E$. coli adopts mild conditions, which contributes to save energy and cost.

Future research would be made with focus on two components. Firstly, the XOS concentration could be further improved. For example, many other xylanases, substrates, pretreatments or mediums are alternative for fermentation [35]. In particular, the plasmid is worth optimizing. $\mathrm{pET} 22 \mathrm{~b}(+)$ was used for constructing recombinant $E$. coli in this study. Strictly speaking, it is not an ideal plasmid for secretory expression because only a small part, about 30\% according to our measurement, of recombinant proteins was transported into medium. Developing more appropriate plasmids for production is very promising to improve the yield. Secondly, application prospect of such one-step fermentation needs to be evaluated at larger scale. It is obvious that a good XOS yield derived from triangular flasks is no guarantee of the same thing at industrial level. A test using lab-scale fermentation tank is constructive research as well as the first step to promote it from laboratory to factory.

\section{Conclusions}

This work demonstrates that E. coli is appropriate for producing XOS with a competitive concentration thereby overcoming the current weakness of one-step fermentation. The critical factor leading to the breakthrough in yield is efficient production of XOS by E. coli at high substrate concentration. The optimal conditions, especially $\mathrm{pH}$, for fermentation are highly affected by enzymatic characteristics of the xylanase used. This work provides theoretical basis for overcoming yield and cost challenge, and contributes to the wide adoption of XOS.

\section{Methods}

\section{Strains, plasmid, and substrates}

B. agaradhaerens C9 was isolated from saline-alkali soil, and has been maintained in our laboratory since then [36]. E. coli $\mathrm{DH} 5 \alpha$ was used for gene cloning and plasmid maintenance. E. coli BL21(DE3) was used for gene expression as well as fermentation. pET22b $(+)$, which was previously used for extracellular production of recombinases in many researches $[37,38]$, was employed for constructing recombinant plasmid.

Arabinoxylan, glucuronoxylan and XOS with DP ranging from 2 to 6 were all purchased from Megazyme (Ireland). Wheat bran was purchased from a flour mill in Huainan city, China. Starch presenting in wheat bran was removed according to the reported method before fermentation [39]. In brief, milled wheat bran was treated with amylase and papain successively. These enzymes were then denatured by boiling for $25 \mathrm{~min}$. After that, wheat bran was washed three times to remove enzymes and starch. The de-starched wheat bran was finally dried and screened through 80 meshes sieve for fermentation and hydrolysis. Xylan content of wheat bran increased from 28.3 to $59.4 \%$ after de-starched treatment, which was measured according to the method offered by National Renewable Energy Laboratory [40].

\section{Heterologous expression and purification}

Sequence of Baxyl11 gene is accessible in raw data and it is predicted as xylanase basing on BLAST (https:// blast.ncbi.nlm.nih.gov/Blast.cgi). The gene was cloned with forward primer containing BamHI restriction site (5'-CTAGGATCCGCAAATCGTCACCGACAATTC CA- $\left.3^{\prime}\right)$ and reverse primer containing $X h o I$ restriction site (5'-CCGCTCGAGATTGTTTTTGTCCAAAGT TAT- $\left.3^{\prime}\right)$. Baxyl11 gene was ligated into pET22b(+) after digested by endonucleases, and then transferred into E. coli $\mathrm{DH} 5 \alpha$. The validated recombinant plasmid was 
finally transferred into E. coli BL21(DE3) for heterologous expression.

Inducing Baxyl11 gene expression was carried out in LB-ampicillin medium containing $0.6 \mathrm{mM}$ of IPTG at $37^{\circ} \mathrm{C}, 200 \mathrm{rpm}$ for $6 \mathrm{~h}$. Bacterial cells were then harvested by centrifugation, and were resuspended using Tris- $\mathrm{HCl}$ buffer $(20 \mathrm{mM}, \mathrm{pH} 8.0)$ for ultrasonication. After that, soluble cell extract containing rBaxyl11 was collected by centrifuging at $4{ }^{\circ} \mathrm{C}$ and was filtered through $0.45-\mu \mathrm{m}$ filters. $\mathrm{r} B a x y l 11$ was purified by affinity chromatography as follows: $5 \mathrm{~mL}$ of soluble cell extract was loaded into a $\mathrm{Ni}-\mathrm{NTA}$ column that was previously equilibrated with binding buffer ( $20 \mathrm{mM}$ Tri- $\mathrm{HCl}, 500 \mathrm{mM} \mathrm{NaCl}, \mathrm{pH} 8.0)$. $12 \mathrm{~mL}$ of washing buffer (20 mM imidazole, $20 \mathrm{mM}$ Tri$\mathrm{HCl}, 500 \mathrm{mM} \mathrm{NaCl}, \mathrm{pH} 8.0)$ and $6 \mathrm{~mL}$ of elution buffer (250 mM imidazole, $20 \mathrm{mM}$ Tri- $\mathrm{HCl}, 500 \mathrm{mM} \mathrm{NaCl}, \mathrm{pH}$ 8.0) were then loaded to remove undesired proteins and to elute $r$ Baxyl11, respectively. Saline ions in eluent were removed by dialysis and $\mathrm{r} B a x y l 11$ was finally freeze-dried for reserve.

The purified $\mathrm{r} B a x y l 11$ was detected by sodium dodecyl sulfate polyacrylamide gel electrophoresis. In brief, 15 $\mu \mathrm{L}$ of $\mathrm{r}$ Baxyl11 solution was mixed with $5 \mu \mathrm{L}$ of loading buffer and then incubated in boiling water bath for $5 \mathrm{~min}$. After that, the protein solution was load into a polyacrylamide gel (12.5\%) for electrophoresis. The gel was dyed using coomassie blue solution to detect the band of protein.

\section{Enzyme assay}

The freeze-dried rBaxyl11 was dissolved using deionized water, and protein concentration was determined according to the absorbancy at $280 \mathrm{~nm}$ and the extinction coefficient of $r$ Baxyl11. To measure enzymatic activity, $50 \mu \mathrm{L}$ of diluted enzyme solution and $100 \mu \mathrm{L}$ of substrate solution were mixed and incubated at $60{ }^{\circ} \mathrm{C}$, $\mathrm{pH} 8.0$ for $20 \mathrm{~min}$, and the reducing sugars were then measured with dinitrosalicylic acid (DNS) assay and calibration curve using xylose as standard [41]. Kinetic parameters were worked out using Lineweaver-Burk plot according to enzyme activities which were measured with xylan solution whose concentration ranged from 1 to $20 \mathrm{mg} / \mathrm{mL}$ [42]. The optimal reaction conditions were investigated by determining enzymatic activities at different temperatures or $\mathrm{pH}$ values. To study stability, activities of $\mathrm{rBaxyl11}$ were measured after incubated at $70{ }^{\circ} \mathrm{C}\left(\mathrm{Na}_{2} \mathrm{HPO}_{4}-\mathrm{NaH}_{2} \mathrm{PO}_{4}\right.$ buffer, $\mathrm{pH}$ 8.0) for different time or incubated in buffers $\left(\mathrm{Na}_{2} \mathrm{HPO}_{4}-\mathrm{NaH}_{2} \mathrm{PO}_{4}\right.$ buffer and $\mathrm{Na}_{2} \mathrm{CO}_{3}-\mathrm{NaHCO}_{3}$ buffer) with different $\mathrm{pH}$ (5.010.0) value for one hour.

XOS produced by $\mathrm{r} B a x y l 11$ from wheat bran were analyzed using HPIC with a Dionex ICS3000 system. Analytical CarboPac PA10 pellicular anion-exchange resin column ( 250 by $4 \mathrm{~mm}$ ) was used for sugar separation. 25 $\mu \mathrm{L}$ of sample was eluted with $250 \mathrm{mM} \mathrm{NaOH}(1.0 \mathrm{~mL} /$ min) at $30{ }^{\circ} \mathrm{C}$ and detected by ED 3000 pulsed amperometric detector.

\section{One-step fermentation}

One-step fermentation was carried out as following method if not specifically indicated. Recombinant E. coli BL21(DE3) was inoculated into LB-ampicillin medium and grown at $37^{\circ} \mathrm{C}$ overnight. Then, appropriate amounts of cells were collected by centrifugation and further diluted to an initial $\mathrm{OD}_{600}=1.0$ into fermentation medium. After that, ampicillin and IPTG were respectively added to $50 \mu \mathrm{g} / \mathrm{mL}$ and $0.6 \mathrm{mM}$, and cells were cultured at $37{ }^{\circ} \mathrm{C}$ and $200 \mathrm{rpm}$ immediately. After $12 \mathrm{~h}$, supernatant of medium was diluted to measure extracellular xylanase activity and XOS concentration (equivalent xylose) as the method introduced in "One-step fermentation" section. Medium before fermentation was used as control group for measurement of reducing sugar. Each liter of fermentation medium contains: $20 \mathrm{~g}$ wheat bran, $4.8 \mathrm{~g} \mathrm{Na}_{2} \mathrm{HPO}_{4} \cdot 12 \mathrm{H}_{2} \mathrm{O}, 2.65 \mathrm{~g} \mathrm{KH}_{2} \mathrm{PO}_{4}, 4 \mathrm{~g}\left(\mathrm{NH}_{4}\right)_{2} \mathrm{SO}_{4}$, $0.3 \mathrm{~g} \quad \mathrm{MgSO}_{4} \cdot 7 \mathrm{H}_{2} \mathrm{O}, \quad 0.01 \mathrm{~g} \quad \mathrm{FeSO}_{4} \cdot 7 \mathrm{H}_{2} \mathrm{O}, 0.01 \mathrm{~g}$ $\mathrm{CaCl}_{2} \cdot 2 \mathrm{H}_{2} \mathrm{O}$ and $1 \mathrm{~mL}$ trace element solution $(0.3 \mathrm{~g} / \mathrm{L}$ $\mathrm{H}_{3} \mathrm{BO}_{3}, 0.2 \mathrm{~g} / \mathrm{L} \mathrm{CoCl}_{2} \cdot 6 \mathrm{H}_{2} \mathrm{O}, 30 \mathrm{mg} / \mathrm{L} \mathrm{ZnSO}_{4} \cdot 7 \mathrm{H}_{2} \mathrm{O}$, $30 \mathrm{mg} / \mathrm{L} \mathrm{MnCl}{ }_{2} \cdot 4 \mathrm{H}_{2} \mathrm{O}, 30 \mathrm{mg} / \mathrm{L} \mathrm{NaMoO}{ }_{4} \cdot 2 \mathrm{H}_{2} \mathrm{O}, 20 \mathrm{mg} / \mathrm{L}$ $\mathrm{NiCl}_{2} \cdot 6 \mathrm{H}_{2} \mathrm{O}$ and $10 \mathrm{mg} / \mathrm{L} \mathrm{CuSO} \cdot 5 \mathrm{H}_{2} \mathrm{O}$ ). The $\mathrm{pH}$ value of fermentation medium was adjusted to 7.0 before sterilization. To investigate the optimal nitrogen source, $\mathrm{NH}_{4} \mathrm{SO}_{4}$ in initial medium was replaced with equal-mass tryptone, casein acids hydrolysate, yeast extract, urea, beef extract, $\mathrm{NH}_{4} \mathrm{NO}_{3}, \mathrm{NaNO}_{3}$ or glycine for fermentation and the medium without additional nitrogen source was used as control. All experiments were performed in triplicate.

\section{Measurement of biomass}

Growth of E. coli was measured by dilute plate method. $100 \mu \mathrm{L}$ of medium after fermentation was sampled and diluted $10^{5}-10^{7}$ times using $\mathrm{NaCl}$ solution (0.9\%). $200 \mu \mathrm{L}$ of diluted medium was spread onto a LB-ampicillin agar plate and cultured at $37{ }^{\circ} \mathrm{C}$ overnight. Colony forming unit (CFU) was finally counted to evaluate the biomass of E. coli in medium after fermentation.

\section{Optimization of XOS production}

Response surface methodology was employed to optimize XOS production by one-step fermentation using Box-Behnken experimental design [20]. Nitrogen source concentration, $\mathrm{pH}$ and fermentation temperature were selected for optimization. Experimental design was provided in Table 2, and the range of these factors was chosen basing on pretest. 


\section{Bioinformatic and statistical analysis}

Signal peptide was predicted using Signalp 4.0 server (http://www.cbs.dtu.dk/services/SignalP-4.0/). Glycoside hydrolase family was predicted using dbCAN meta server (http://bcb.unl.edu/dbCAN2/blast.php). Sequence alignment was carried out using DNAMAN v6 software package. Statistical analysis was carried out using t-test (least significant difference).

\begin{abstract}
Abbreviations
CFU: Colony forming unit; DNS: 3,5-Dinitrosalicylic acid; DP: Degree of polymerization; GH: Glycoside hydrolase; HPIC: High pressure ion chromatography; IPTG: Isopropyl-1-thio- $\beta$-D-galactopyranoside; pNPX: 4-Nitrophenyl-beta-Dxylopyranoside; XOS: Xylo-oligosaccharides.
\end{abstract}

\section{Supplementary Information}

The online version contains supplementary material available at https://doi. org/10.1186/s12896-022-00736-8.

Additional file 1: Fig. S1 Effect of IPTG concentration on XOS yield and xylanase activity of fermentation.

\section{Acknowledgements}

Not applicable.

\section{Authors' contributions}

$J$ designed the work. CL drafted the work. SQ, ZD and DS performed the experiments. JZ analyzed and interpreted the data; $\mathrm{WL}$ revised the manuscript. All authors read and approved the final manuscript.

\section{Funding}

This study is supported by The Natural Science Foundation of the Jiangsu Higher Education Institutions of China (20KJB180001; 20KJA180007); National Natural Science Foundation of China (31970036, 31900401 and 31800020), Natural Science Foundation of Jiangsu Province (BK20171163, BK20181009), Natural Science Foundation of Xuzhou city (KC19196), Six Talent Peaks Project of Jiangsu Province (JNHB-103).

\section{Availability of data and materials}

Raw data are available at https://doi.org/10.6084/m9.figshare.16779289.v1

\section{Declarations}

Ethics approval and consent to participate

Not applicable.

\section{Consent for publication}

Not applicable.

\section{Competing interests}

The authors declare that they have no competing interests.

Received: 1 October 2021 Accepted: 28 January 2022

Published online: 05 February 2022

\section{References}

1. Gibson GR, Scott KP, Rastall RA, Tuohy KM, Hotchkiss A, Dubert-Ferrandon A, Gareau M, Murphy EF, Saulnier D, Loh G, et al. Dietary prebiotics: current status and new definition. Food Sci Technol Bull Funct Foods. 2010;7(1):1-19. https://doi.org/10.1616/1476-2137.15880.
2. Wu Y, Li SJ, Tao Y, Li DD, Han YB, Show PL, Wen GZ, Zhou JZ. Fermentation of blueberry and blackberry juices using Lactobacillus plantarum, Streptococcus thermophilus and Bifidobacterium bifidum: growth of probiotics, metabolism of phenolics, antioxidant capacity in vitro and sensory evaluation. Food Chem. 2021;348(4):129083. https://doi.org/10.1016/j.foodc hem.2021.129083.

3. Davani-Davari D, Negahdaripour M, Karimzadeh I, Seifan M, Mohkam M, Masoumi SJ, Berenjian A, Ghasemi Y. Prebiotics: definition, types, sources, mechanisms, and clinical applications. Foods. 2019;8(3):92. https://doi. org/10.3390/foods8030092.

4. Aachary AA, Prapulla SG. Xylooligosaccharides (XOS) as an emerging prebiotic: microbial synthesis, utilization, structural characterization, bioactive properties, and applications. Compr Rev Food Sci Food Saf. 2011;10(1):2-16. https://doi.org/10.1111/j.1541-4337.2010.00135.x.

5. Wu YL, Chen YN, Lu YF, Hao HL, Liu J, Huang RM. Structural features, interaction with the gut microbiota and anti-tumor activity of oligosaccharides. RSC Adv. 2020;10(28):16339-48. https://doi.org/10.1039/D0RA0 0344A.

6. Cordero G, Kim JC, Whenham N, Masey-O'Neill H, Srinongkote S, Gonzalez-Ortiz G. Xylanase and fermentable xylo-oligosaccharides improve performance in grower-finisher pigs fed a corn-soybean meal based diet. J Anim Sci. 2019;97:91-2. https://doi.org/10.1093/jas/skz122.166.

7. Jia CS, Cao DD, Ji SP, Lin WT, Zhang XM, Muhoza B. Whey protein isolate conjugated with xylo-oligosaccharides via maillard reaction: characterization, antioxidant capacity, and application for lycopene microencapsulation. LWT-Food Sci Technol. 2020;1 18(4):108837. https://doi.org/10.1016/j. Iwt.2019.108837.

8. de Figueiredo FC, Ranke FFD, de Oliva-Neto P. Evaluation of xylooligosaccharides and fructooligosaccharides on digestive enzymes hydrolysis and as a nutrient for different probiotics and Salmonella typhimurium. LWT-Food Sci Technol. 2020;1 18:108761. https://doi.org/10.1016/j.lwt. 2019.108761.

9. Makelainen H, Forssten S, Saarinen M, Stowell J, Rautonen N, Ouwehand AC. Xylo-oligosaccharides enhance the growth of bifidobacteria and Bifidobacterium lactis in a simulated colon model. Benefic Microbes. 2010;1(1):81-91. https://doi.org/10.3920/BM2009.0025.

10. Pan X, Wu T, Zhang L, Cai L, Song Z. Influence of oligosaccharides on the growth and tolerance capacity of Lactobacilli to simulated stress environment. Lett Appl Microbiol. 2009;48(3):362-7. https://doi.org/10.1111/j. 1472-765X.2008.02539.x.

11. Courtin CM, Swennen K, Verjans P, Delcour JA. Heat and pH stability of prebiotic arabinoxylooligosaccharides, xylooligosaccharides and fructooligosaccharides. Food Chem. 2009;112(4):831-7. https://doi.org/10.1016/j. foodchem.2008.06.039.

12. Amorim C, Silverio SC, Prather KLJ, Rodrigues LR. From lignocellulosic residues to market: production and commercial potential of xylooligosaccharides. Biotechnol Adv. 2019;37(7):107397. https://doi.org/10.1016/j. biotechadv.2019.05.003.

13. Santibanez L, Henriquez C, Corro-Tejeda R, Bernal S, Armijo B, Salazar O. Xylooligosaccharides from lignocellulosic biomass: a comprehensive review. Carbohydr Polym. 2021;251:117118. https://doi.org/10.1016/j. carbpol.2020.117118.

14. Karlsson EN, Schmitz E, Linares-Pasten JA, Adlercreutz P. Endo-xylanases as tools for production of substituted xylooligosaccharides with prebiotic properties. Appl Microbiol Biotechnol. 2018;102(32):9081-8. https://doi. org/10.1007/s00253-018-9343-4.

15. Madan B, Lee SG. Sequence and structural features of subsite residues in GH10 and GH11 xylanases. Biotechnol Bioprocess Eng. 2018;23(3):311-8. https://doi.org/10.1007/s12257-018-0105-z.

16. Ma R, Bai YG, Huang HQ, Luo HY, Chen SF, Fan YL, Cai L, Yao B. Utility of Thermostable xylanases of Mycothermus thermophilus in generating prebiotic xylooligosaccharides. J Agric Food Chem. 2017;65(6):1139-45. https://doi.org/10.1021/acs.jafc.6b05183.

17. Mkabayi L, Malgas S, Wilhelmi BS, Pletschke BI. Evaluating feruloyl esterase-xylanase synergism for hydroxycinnamic acid and xylooligosaccharide production from untreated, hydrothermally pre-treated and dilute-acid pre-treated corn cobs. Agronomy-Basel. 2020;10(5):688. https://doi.org/10.3390/agronomy10050688.

18. Kumar V, Satyanarayana T. Generation of xylooligosaccharides from microwave irradiated agroresidues using recombinant thermo-alkali-stable endoxylanase of the polyextremophilic bacterium Bacillus halodurans 
expressed in Pichia pastoris. Bioresour Technol. 2015;179:382-9. https:// doi.org/10.1016/j.biortech.2014.12.049.

19. Liu XQ, Liu Y, Jiang ZQ, Liu HJ, Yang SQ, Yan QJ. Biochemical characterization of a novel xylanase from Paenibacillus barengoltzii and its application in xylooligosaccharides production from corncobs. Food Chem. 2018;264:310-8. https://doi.org/10.1016/j.foodchem.2018.05.023.

20. Amorim C, Silverio SC, Silva SP, Coelho E, Coimbra MA, Prather KL Rodrigues LR. Single-step production of arabino-xylooligosaccharides by recombinant Bacillus subtilis 3610 cultivated in brewers'spent grain. Carbohydr Polym. 2018;199:546-54. https://doi.org/10.1016/j.carbpol. 2018.07.017.

21. Amorim C, Silverio SC, Rodrigues LR. One-step process for producing prebiotic arabino-xylooligosaccharides from brewer's spent grain employing Trichoderma species. Food Chem. 2019;270:86-94. https://doi. org/10.1016/j.foodchem.2018.07.080.

22. Menezes BD, Rossi DM, Squina F, Ayub MAZ. Comparative production of xylanase and the liberation of xylooligosaccharides from lignocellulosic biomass by Aspergillus brasiliensis BLf1 and recombinant Aspergillus nidulans XynC A773. Int J Food Sci Technol. 2018;53(9):2110-8. https:// doi.org/10.1111/ijfs.13798.

23. Huang $\mathrm{CJ}$, Lin $\mathrm{H}$, Yang XM. Industrial production of recombinant therapeutics in Escherichia coli and its recent advancements. J Ind Microbiol Biotechnol. 2012;39(3):383-99. https://doi.org/10.1007/ s10295-011-1082-9.

24. Xu J, Yu H, Chen X, Liu L, Zhang W. Accelerated green process of 2,5-dimethylpyrazine production from glucose by genetically modified Escherichia coli. ACS Synth Biol. 2020;9:2576-87. https://doi.org/10.1021/ acssynbio.0c00329.

25. Falck P, Precha-Atsawanan S, Grey C, Immerzeel P, Stalbrand H, Adlercreutz P, Karlsson EN. Xylooligosaccharides from hardwood and cereal xylans produced by a thermostable xylanase as carbon sources for Lactobacillus brevis and Bifidobacterium adolescentis. J Agric Food Chem. 2013;61(30):7333-40. https://doi.org/10.1021/jf401249g.

26. Wang RN, Yang JS, Jang JM, Liu JW, Zhang Y, Liu L, Yuan HL. Efficient ferulic acid and xylo-oligosaccharides production by a novel multi-modular bifunctional xylanase/feruloyl esterase using agricultural residues as substrates. Bioresour Technol. 2020;297(5):122487. https://doi.org/10. 1016/j.biortech.2019.122487.

27. Tran TN, Doan CT, Wang SL. Conversion of wheat bran to xylanases and dye adsorbent by Streptomyces thermocarboxydus. Polymers. 2021;13(2):287. https://doi.org/10.3390/polym13020287.

28. Liu C, Hao Y, Jiang JH, Liu WJ. Valorization of untreated rice bran towards bioflocculant using a lignocellulose-degrading strain and its use in microalgal biomass harvest. Biotechnol Biofuels. 2017;10(1):90. https://doi.org/ 10.1186/s13068-017-0780-6.

29. Rajagopalana G, Shanmugavelu K, Yang KL. Production of prebioticxylooligosaccharides from alkali pretreated mahogany and mango wood sawdust by using purified xylanase of Clostridium strain $\mathrm{BOH}$. Carbohydr Polym. 2017;167:158-66. https://doi.org/10.1016/j.carbpol.2017.03.021.

30. Reque PM, Pinilla CMB, Gauterio GV, Kalii SJ, Brandelli A. Xylooligosaccharides production from wheat middlings bioprocessed with Bacillus subtilis. Food Res Int. 2019;126:108673. https://doi.org/10.1016/j.foodres. 2019.108673.

31. Poon DKY, Webster P, Withers SG, McIntosh LP. Characterizing the $\mathrm{pH}$-dependent stability and catalytic mechanism of the family 11 xylanase from the alkalophilic Bacillus agaradhaerens. Carbohydr Res. 2003;338(5):415-21. https://doi.org/10.1016/S0008-6215(02)00486-X.

32. Ho AL, Kosik O, Lovegrove A, Charalampopoulos D, Rastall RA. In vitro fermentability of xylo-oligosaccharide and xylo-polysaccharide fractions with different molecular weights by human faecal bacteria. Carbohydr Polym. 2018;179:50-8. https://doi.org/10.1016/j.carbpol.2017.08.077.

33. Iliev I, Vasileva T, Bivolarski V, Momchilova A, Ivanova I. Metabolic profiing of xylooligosaccharides by Lactobacilli. Polymers. 2020;12(10):2387. https://doi.org/10.3390/polym12102387.

34. Yang ZG, Cao LM, Li Y, Zhang M, Zeng FY, Yao SQ. Effect of pH on hemicellulose extraction and physicochemical characteristics of solids during hydrothermal pretreatment of eucalyptus. BioResources 2020;15(3):6627-35. https://doi.org/10.15376/biores.15.3.6627-6635.

35. Phwan CK, Chew KW, Sebayang AH, Ong HC, Ling TC, Malek MA, Ho YC, Show PL. Effects of acids pre-treatment on the microbial fermentation process for bioethanol production from microalgae. Biotechnol Biofuels. 2019;12(1):191. https://doi.org/10.1186/s13068-019-1533-5.

36. Liu C, Wang K, Jiang JH, Liu WJ, Wang JY. A novel bioflocculant produced by a salt-tolerant, alkaliphilic and biofilm-forming strain Bacillus agaradhaerens $\mathrm{C} 9$ and its application in harvesting Chlorella minutissima UTEX2341. Biochem Eng J. 2015;93:166-72. https://doi.org/10.1016/j.bej. 2014.10.006.

37. Zhen J, Tan M, Fu XP, Shu WJ, Zhao XY, Yang SB, Xu JY, Ma YH, Zheng HC, Song $\mathrm{H}$. High-level extracellular production of an alkaline pectate lyase in E. coli BL21 (DE3) and its application in bioscouring of cotton fabric. 3 Biotech. 2020;10(2):49. https://doi.org/10.1007/s13205-019-2022-z.

38. Zheng HC, Yu ZX, Fu XP, Li SF, Xu JY, Song H, Ma YH. High level extracellular production of a truncated alkaline beta-mannanase from alkaliphilic Bacillus sp N16-5 in Escherichia coli by the optimization of induction condition and fed-batch fermentation. J Ind Microbiol Biotechnol. 2016;43(7):977-87. https://doi.org/10.1007/s10295-016-1773-3.

39. Xu ZS, Wang T, Zhang SS. Extracellular secretion of feruloyl esterase derived from Lactobacillus crispatus in Escherichia coli and its application for ferulic acid production. Bioresour Technol. 2019;288:121526. https:// doi.org/10.1016/j.biortech.2019.121526.

40. Sluiter JB, Ruiz RO, Scarlata CJ, Sluiter AD, Templeton DW. Compositional analysis of lignocellulosic feedstocks. 1. Review and description of methods. J Agric Food Chem. 2010;58(6):9043-53. https://doi.org/10.1021/ jf1008023.

41. Miller GL. Use of dinitrosalicylic acid reagent for determination of reducing sugar. Anal Chem. 1959;31:426-8.

42. Wu B, Zheng S, Pedroso MM, Guddat LW, Chang SY, He BF, Schenk G. Processivity and enzymatic mechanism of a multifunctional family 5 endoglucanase from Bacillus subtilis BS-5 with potential applications in the saccharification of cellulosic substrates. Biotechnol Biofuels. 2018;11(1):20. https://doi.org/10.1186/s13068-018-1022-2.

43. Hesam F, Tarzi BG, Honarvar M, Jahadi M. Pistachio (Pistacia vera) shell as a new candidate for enzymatic production of xylooligosaccharides. J Food Meas Charact. 2021;15(1):33-45. https://doi.org/10.1007/ s11694-020-00594-y.

44. Bragatto J, Segato F, Squina FM. Production of xylooligosaccharides (XOS) from delignified sugarcane bagasse by peroxide-HAc process using recombinant xylanase from Bacillus subtilis. Ind Crops Prod. 2013;51:1239. https://doi.org/10.1016/j.indcrop.2013.08.062.

45. Kumar B, Bhardwaj N, Verma P. Microwave assisted transition metal salt and orthophosphoric acid pretreatment systems: generation of bioethanol and xylo-oligosaccharides. Renew Energ. 2020;158:574-84. https:// doi.org/10.1016/j.renene.2020.05.006.

46. Le B, Yang SH. Production of prebiotic xylooligosaccharide from aqueous ammonia-pretreated rice straw by beta-xylosidase of Weissella cibaria. J Appl Microbiol. 2019;126(6):1861-8. https://doi.org/10.1111/jam.14255.

47. Khangwal I, Nath S, Kango N, Shukla P. Endo-xylanase induced xylooligosaccharide production from corn cobs, its structural features, and concentration-dependent antioxidant activities. Biomass Convers Biorefin. 2020. https://doi.org/10.1007/s13399-020-00997-3.

48. Ataei $D$, Hamidi-Esfahani Z, Ahmadi-Gavlighi H. Enzymatic production of xylooligosaccharide from date (Phoenix dactylifera L.) seed. Food Sci Nutr. 2020;8(2):6699-707. https://doi.org/10.1002/fsn3.1964.

49. Patipong T, Lotrakul P, Padungros P, Punnapayak H, Bankeeree W, Prasongsuk S. Enzymatic hydrolysis of tropical weed xylans using xylanase from Aureobasidium melanogenum PBUAP46 for xylooligosaccharide production. 3 Biotech. 2019;9(2):56. https://doi.org/10.1007/s13205-019-1586-y.

\section{Publisher's Note}

Springer Nature remains neutral with regard to jurisdictional claims in published maps and institutional affiliations. 